Izvirni znanstveni članek Original scientific paper (1.01) Besedilo prejeto Received: 2. 11. 2020; Sprejeto Accepted: 11. 11. 2020 UDK UDC: 26"653"(497.12Štajerska) DOI: 10.34291/Edinost/76/Ravnikar (C) 2021 Ravnikar CC BY 4.0

\title{
Tone Ravnikar
}

\section{Judje v manjših štajerskih mestih v srednjem veku}

\author{
Jews in Smaller Styrian Towns in the Middle Ages
}

Izvleček: Za nalogo smo si v razpravi zadali odgovoriti na nekaj ključnih vprašanj, vezanih predvsem na čas in vzrok prihoda judov v posamezne spodnještajerske urbane kraje. Kot vzorčne primere smo izbrali manjše kraje, kjer je judovska navzočnost zabeležena v dokumentih. Zaključiti smemo, da se vloga deželnih gospodov, predvsem Habsburžanov, kaže kot ključna pri spodbujanju in podpiranju judov pri odločitvi, da se naselijo v določenem kraju. To se verjetno najbolj jasno vidi pri različnih zgodbah dveh mejnih mestec, Ormoža in Brežic, obeh v lasti salzburškega nadškofa. Obe mesti sta torej last salzburškega nadškofa, toda če se je Ormož predvsem zaradi samosvoje politike družine Ptujskih in njihove naslonitve na štajerske vojvode tesne zveze s Salzburgom v veliki meri otresel, je ta podreditev oz. salzburška nadvlada ostala v Brežicah zelo izrazita. To povzroči, da v Ormožu pride do poskusa (sicer relativno kratkotrajnega, pa vendar) nastanka ormoške judovske skupnosti, medtem ko v Brežicah ni o čem podobnem ne duha ne sluha.

Angažma štajerskih vojvod pa je najbolje viden na primeru (Slovenske) Bistrice, kjer je očitno, da je ravno njihov interes tisti, ki je ne samo omogočil prihod judov v mesto, temveč tudi $\mathrm{v}$ veliki meri uravnaval njihovo delovanje.

Tudi primer Slovenj Gradca kaže na podoben vzorec. Tudi tu je za prihod judov v mesto odločilen vpliv deželnega gospoda, le da je ta v tem primeru izražen posredno, skozi delovanje deželnoministerialne družine Aufensteinov, ki pa je bilo brez dvoma povsem usklajeno z željami njihovega gospoda, koroškega vojvode. Iz celotne slike še najbolj izstopa primer Dravograda, kjer imamo opravka z dokaj nenavadnim momentom, ko se, kot kaže, štajerski judje (vsaj tako kaže dejstvo, da se podredijo sodniku za jude iz Gradca) naselijo v kraju. Ravno primer Dravograda tudi kaže, kako majhno količino podatkov imamo na razpolago, saj ni jasen niti čas prihoda in s tem dolgotrajnost tega niti povezava dravograjskih judov z morebitnimi skupnostmi iz koroškega oz. štajerskega prostora. Usoda juda Davida iz Dravograda na Dunaju kaže le na to, da je bila njegova povezanost z Dravogradom zelo velika in je morala presegati zgolj kratkotrajno bivanje.

Vsekakor pa je mogoče zaključiti, da ne samo, da je bila vloga deželnih gospodov (pričakovano) tista, ki je v največji meri krojila prisotnost oz. neprisotnost judov po posameznih krajih, temveč tudi to, da je še prav posebej izpostavljena vloga Habsburžanov (in Tirolskih kot koroških vojvod) kot štajerskih deželnih gospodov. Različna pristopa k (ne)prisotnosti judov lahko vidimo skozi primerjavo salzburških Brežic, kjer jude zaman iščemo, in salzburškega Ormoža, kjer so prisotni v 14. stoletju. Poudarjeno vlogo Habsburžanov pa nam prinaša tudi analiza gradiva mesta Slovenska Bistrica. Vsekakor pa bo za več odgovorov treba tej analizi dodati še podobno za kranjsko deželo in za prostor Goriške in Istre. 
Ključne besede: srednji vek, mesta, judje, Štajerska, Koroška

Abstract: For the purpose of this paper, we have set out to answer some key questions of the debate, mainly relating to the timing and cause of the arrival of the Jews in individual smaller urban locations. We have selected smaller cities where the Jewish presence is recorded in the documents as prime examples. We have to note that the role of the sovereigns, especially the Habsburgs, has proved to be crucial in encouraging and supporting the Jews in their decision to settle in a particular place. This is probably most evident in the different histories of the two border towns of Ormož and Brežice, both of which are owned by the Archbishop of Salzburg. Both towns are therefore owned by the Archbishop of Salzburg, but while Ormož was largely owned by the Ptuj family and their close ties with Salzburg were largely shaken due to their support on Styrian Dukes, the subjugation of the Salzburg rule in Brežice remained very pronounced. This is also shown by the fact that Ormož (though relatively short-lived) experienced the formation of the Jewish community of Ormož, while there is nothing comparable in Brežice. However, the commitment of Styrian Dukes seems to be best in the case of the (Slovenian) Bistrica, where it is clear that their interest that has not only made the arrival of Jews in the town possible, but also largely regulated their activities.

The case of Slovenj Gradec also points to a similar pattern. Here, too, the influence of the landed gentry is decisive for the arrival of the Jews in the city, but in this case it is indirectly expressed through the actions of the Aufensteiner landed gentry, which was undoubtedly entirely in the spirit of their master, the Duke of Carinthia. From the overall picture, the example of Dravograd stands out most, where we are dealing with a rather unusual moment when the Jews from Styria (at least as the fact that they are subject to the judge for the Jews of Graz) settle down in one place. Especially the example of Dravograd shows how small the amount of data is, because neither the time of arrival and thus the longevity of the data is clear, nor the connection of Dravograd Jews with potential communities from Carinthia or Styria. The fate of Jew David from Dravograd in Vienna only shows that the connection with Dravograd was very tight and had to go beyond a purely short-term stay.

In any case, it can be concluded that it was not only the role of Provincial Lords that largely controlled the presence or absence of Jews in individual places, but that the role of the Habsburgs (and Tyroleans as Dukes of Carinthia) as Styrian sovereigns is also particularly exposed. Different approaches to the (non-)presence of Jews can be seen in the comparison of the Salzburg town of Brežic, where Jews are freely sought, and the Salzburg town of Ormož, where they were freely sought in the $14^{\text {th }}$ century. The emphasis on the Habsburgs is also brought to our attention by the analysis of the material of the town Slovenska Bistrica In any case, this analysis must be added for further answers in a similar way for the Kranjska region and for the Goriška and Istra regions.

Key words: Middle Ages, Towns, Jews, Styria, Carinthia

\section{Uvod}

Tema judovske navzočnosti na slovenskih tleh v srednjem veku ni nova tema v slovenskem zgodovinopisju. Omenimo samo dve, ${ }^{1}$ verjetno temeljni deli starejšega zgodovinopisja na temo Judov, razpravo Vlada Valenčiča Židje v preteklosti Ljubljane (1992) ter Vladimirja Travnerja Mariborski

1 Namerno se osredotočamo le na čas znanstvenega zgodovinopisja in izpuščamo pregled starejših avtorjev, od Valvazorja dalje. Tak pregled bi bistveno povečal obseg razprave, ne bi pa prinesel pomembnejših dodatnih spoznanj.

Edinost in dialog 76 (2021) 1: 219-241 
ghetto (1935). Kljub relativno zgodnjemu nastanku Travnerjevega besedila pa je bila vendar v slovenskem zgodovinopisju tema o judih relativno zapostavljena. Nenazadnje je tudi Valenčičeva razprava ostala v tipkopisu in je danes dostopna le v tej obliki oz. jo je Zgodovinski arhiv v Ljubljani v svoji Zbirki rokopisnih elaboratov objavil na spletu. Zgodovinarji, ki so delovali v času po drugi svetovni vojni, se z vprašanji navzočnosti ter vloge judov v srednjeveški zgodovini slovenskega prostora niso ukvarjali sistematično in podrobno. Edina izjema je navedena Valenčičeva razprava. Obletnica izgona judov iz slovenskih dežel pa je to spremenila. Leta 1996 je namreč minilo 500 let, odkar je kralj Maksimilijan I. podpisal listino o izgonu judov iz Štajerske in Koroške, leta 1515 pa je že kot cesar odločil tudi o izgonu judov še iz dežele Kranjske. Ta okrogli jubilej so izkoristili tudi slovenski zgodovinarji in pripravili simpozij v Mariboru. Razprave iz tega simpozija so nato izšle leta 2000 v posebni številki Časopisa za zgodovino in narodopisje. V tej številki je objavljena tudi pomembna razprava Jožeta Mlinariča o judih na slovenskem Štajerskem (2000, 49-70), poleg te pa tudi razprava Wilhelma Wadla o koroških judih (2000, 95-105), ki predstavlja neke vrste povzetek njegovega temeljnega dela o judih na Koroškem (1992). In prav ti dve pokrajini, slovenska Štajerska in slovenska Koroška, sta v središču zanimanja pričujočega prispevka. Preden sežemo v samo vsebino, naj opozorimo še na dve pomembni deli. Govorimo o najbolj temeljiti monografiji o srednjeveških mestih na slovenskem Štajerskem, ki je sicer delo graškega zgodovinarja in arhivista Norberta Weissa (2002, 130174) in v kateri posveti posebno poglavje ravno judovskim skupnostim v slovenskoštajerskih mestih, ter seveda najpomembnejše delo na temo judov v srednjem veku na Slovenskem, monografsko študijo Klemna Jelinčiča Boete z naslovom Judje na slovenskem v srednjem veku (2009), ki je sploh prva tovrstna celovita študija pri nas. Omenjeni je izdal še več besedil na temo judovske prisotnosti na naših tleh, ki jih na tem mestu ne naštevamo.

Vse obravnavane razprave so se posvečale predvsem definiranju časa in oblike judovske prisotnosti ter so s pomočjo ohranjenega gradiva rekonstruirale časovni in prostorski okvir naselitve. V tej razpravi pa bi želeli fokus gledišča nekoliko spremeniti. Vprašanje, ki si ga zastavljamo, je, zakaj je do naselitve judov v določen kraj prišlo ravno v določenem času in kateri so vplivi, ki vplivajo na to priselitev ali jo celo spodbudijo - torej: zakaj takrat, in ne prej ali kasneje. Naprej, zakaj se judje v nekatere predele 
naseljujejo relativno gosto, ponekod pa jih skoraj ni. Kot primer zgolj naslednje: zakaj je prisotnost judov na Koroškem in na Štajerskem relativno številna, medtem ko jih na Kranjskem najdemo le v Ljubljani, ne pa npr. tudi v Kranju, Kamniku, Škofji Loki ipd.? Oz. če se ozremo na področje, ki je fokus razmišljanja te razprave, zakaj se judje naselijo v obmejnem Ormožu, ne pa v prav tako obmejnih Brežicah? Kaj je bil motiv priselitve? Ali so bili pobudniki naselitve sami judi ali pa je bil pobudnik lastnik oz. zastavni imetnik? Odpira se torej vrsta vprašanj, na katera bomo lahko le delno, če sploh, odgovorili.

\section{Izbrani kraji slovenske Štajerske}

Ker odpiramo torej relativno širok sklop vprašanj, ki bi zahteval več prostora in tudi več časa, se bomo v tej razpravi omejili le na področje današnje slovenske Štajerske in Koroške, in še to le na manjše urbane kraje. Nobenega dvoma ne more biti o motivu, ki je pripeljal jude v npr. Maribor ali Ptuj, dva največja štajerska urbana centra (seveda poleg Gradca). Prav tako sta jasna tako vloga kot motiv žovneških svobodnikov, od leta 1341 grofov Celjskih, da pripeljejo po povzdigu v grofovski stan v svoje Celje prve posojevalce denarja. Naš fokus se bo torej vrtel okoli judov v Slovenski Bistrici, Ormožu, Slovenj Gradcu in Dravogradu. Zastavili si bomo vprašanje, kaj je vzrok, da se judje v omenjenih krajih pojavijo ravno v tistem času. Kateri so gospodarski in/ali politični motivi, ki jim odprejo vrata naselitvi? Ter s tem povezano, kaj je vzrok za njihov odhod iz kraja? Pri tem bo treba tako njihov prihod kot odhod postaviti v širši okvir dogajanja $\mathrm{v}$ posameznem mestu oz. odnosov mesta in mestnega gospoda s sosedi, konkurenti itd. Takoj tudi poudarimo, da smo prisiljeni pristati na kompromisno predpostavko - ki ni nujno točna - da prve omembe judovske prisotnosti v posameznem kraju opredeljujejo v glavnem pravilen časovni okvir njihovega prihoda. Seveda bomo upoštevali vse podatke, ki jih vsebujejo listine in ki olajšujejo odgovore, pa vendar izhajamo iz predpostavke, da je judovska prisotnost v posameznem kraju v glavnem dovolj natančno časovno opredeljena. Taka predpostavka je še posebej problematična pri primeru judov iz Slovenske Bistrice, kjer je prva omemba šele iz leta 1370, vendar je le nekaj let kasneje, leta 1374, že govor tudi o judovskem pokopališču, kar pa že predpostavlja neko etablirano judovsko skupnost. (RGJ 3, št. 1316; št. 1445; Jelinčič Boeta 2009, 288) 
(Slovenska) Bistrica se prvič omenja v virih šele leta 1227, ko je 11. novembra tega leta $v$ Bistrici avstrijski in štajerski vojvoda Leopold VI. Babenberžan izstavil listino v korist Žičke kartuzije (GZS 5, št. 463). Vojvoda se je pred tem nahajal v Mariboru, kjer je štiri dni prej izdal listino v korist jurkloštrske kartuzije, ki ji je na novo začrtal meje, potem ko je jurkloštrskim kartuzijanom povečal posest (Mlinarič 1991, 123-124). Ker vemo, da je vojvoda že 17. novembra leta 1227 listinil v Gradcu (GZS 5, št. 464), smemo povsem logično domnevati, da je iz Bistrice krenil neposredno nazaj na sever. Postavimo si vprašanje, kakšen je motiv, da se je vojvoda iz svojega Maribora napotil na jug do Bistrice ter se nato nemudoma vrnil v Graz. Prav verjeten motiv je, da je bila ta pot povezana z nastankom trga (ali celo mesta) Bistrica, ki ga je vojvoda kot nov deželnoknežji trg še počastil z obiskom. V Leopoldu VI. je videl ustanovitelja Bistrice že Hans Pirchegger, ki ga označuje kar kot »Markt- und Städtegründer«, se pravi ustanovitelj trga in mesta (Bistrica) $(1962,128)$. Pravilno Pirchegger tudi izpostavlja, da je Bistrica, četudi takrat še ni imenovana trg oz. mesto, tak status v tem času skoraj gotovo že pridobila, saj se že leta 1240 omenja sodnik iz Bistrice z imenom Becelin (oblika imena Bernhard), Pirchegger pa vidi tudi v osebi vojvodovega prisednika Georiusa Bistričana (GZS 5, št. 751; Pirchegger 1962, 128), kar pa je vendarle vprašljivo. V vsakem primeru pa smemo leto 1227 z gotovostjo šteti kot tisto, od katerega Bistrica spada med urbane naselbine. Verjetno je bila najkasneje v tem času formirana tudi bistriška fara, ki se z imenom župnika Henrika prvič omenja leta 1252 (StUB III, št. 115). Pri razmisleku o začetkih urbane naselbine v Bistrici moramo upoštevati še en pomemben podatek. Le tri leta preden je vojvoda odpotoval $v$ Bistrico na slavnost ob dvigu naselja med urbane kraje, je isti vojvoda zaključil enega največjih gradbenih podvigov srednjeveškega časa na tleh Slovenije, gradnjo kamnitega mostu čez Savo v Zidanem Mostu. $S$ tem je omogočil najkrajšo povezavo med Celjsko kotlino in Dolenjsko ter Hrvaško ter tako seveda močno okrepil pozicijo svojega gospostva Laško (Kosi 1998, 184-185). Interes nadzorovati cesto med deželnoknežjim Mariborom ter Laškim se je torej še povečal. Ustanovitev še ene urbane naselbine, ki poleg vsega leži ob pomembnem stičišču poti ter neposredno konkurira salzburškemu Ptuju, je torej treba videti v vlogi okrepitve primata vojvode. Ustanovitev urbanega centra v Bistrici se kaže kot povsem logičen in skoraj nujen geostrateški ukrep vojvode. 
Vsaj do srede 13. stoletja je bila Bistrica nato upravljana iz Maribora, najkasneje do leta 1265 pa je bil ustanovljen samostojni urad z glavarjem kot nadzornikom trga/mesta, gospostva in gradu (Kos 2005, 373). O tej spremembi pričata tudi oba deželnoknežja urbarja iz 13. stoletja, kjer je v starejšem, babenberškem, nastalim med 1220 in 1230, slovenskobistriški svet še označen kot pohorska županija, medtem ko je v mlajšem, nastalem med 1265 in 1267 v času vojvodovanja Otakarja Přemysla, že definiran kot urad Bistrica (Koropec 1957, 21-22). Kmalu potem pa je novi avstrijski in nato še štajerski vojvoda, češki kralj Otokar Přemysl, izkoristil urad Bistrica za poplačilo (in nevtraliziranje) Babenberžanke Gertrude, ki bi ga lahko ogrozila v njegovi poziciji v vojvodini Avstriji.

Če zelo na kratko povzamemo. Potem ko si je Otokar uspel zagotoviti oblast nad vojvodino Avstrijo, si je skušal svojo tamkajšnjo oblast utrditi še s poroko. Tako se je februarja $1252 \mathrm{v}$ avstrijskem Hainburgu poročil s 23 let starejšo Babenberžanko Margareto. S tem dejanjem ni le legitimiral svojega vojvodskega naslova (od leta 1253 je sicer nosil tudi naslov češkega kralja), temveč si je pridobil tudi precejšen del deželnoknežjih komornih posesti. Medtem je Margaretina nečakinja Gertruda skušala do babenberške dediščine priti na drugačen način. Postala je namreč zaveznica madžarskega kralja Bele IV. ter se poročila z njegovim sorodnikom, rutenskim knezom Romanom Hališkim. Slednjemu pa se tudi z madžarsko vojaško pomočjo v Avstriji ni uspelo uveljaviti, zato se je od Gertrude kmalu ločil in se odpravil nazaj v domovino (Bele 2018, 27-28).

Več sreče so Madžari imeli s Štajersko, kjer jim je na svojo stran uspelo pritegniti ministeriale na južnem Štajerskem in v Podravju. Otokar se je medtem usidral na severu dotične vojvodine. Mirovni sporazum je bil sklenjen aprila 1254 v Budimu. Otokar je obdržal Avstrijo, kakor tudi območje onstran Aniže z mestoma Steyr in Enns ter posesti v Traungauu, ki so bile prej povezane s Štajersko. Tudi pittensko področje in Dunajsko Novo mesto sta bili zdaj Otokarjevi. Zapuščena Gertruda je v naslednjih letih živela v Voitsbergu in Judenburgu in še naprej uporabljala naziv vojvodinja. Otokar ji je Voitsberg in Judenburg odvzel morda že januarja 1267, namesto tega pa je dobila 400 mark rente, kot novo bivališče pa urad Slovenska Bistrica. Naslednje leto je v Italiji skupaj z zadnjim Staufovcem Konradinom umrl njen sin Friderik. Zdi se, da je Otokar II. zaradi bojazni spričo Gertrudinih zvez z Ogrsko poleti ali jeseni 1269 odredil še njen 
izgon, in Babenberžanka se je bila prisiljena zateči v mejno grofijo Meißen. Slednjič se je umaknila v samostan klaris v Seußlitzu na današnjem Saškem, kjer je umrla, najverjetneje leta 1288. (UBSt III, št. 138; Dopsch 1999, 206-207.307. 447-449)

Bistriški urad je bil torej najkasneje z letom 1269 ponovno "na razpolago«, in res ga Rudolf zastavi enkrat do leta 1276 grofu Meinhardu II. Tirolsko-Goriškem. Slednji je postal leta 1286 koroški vojvoda in zastavni gospod Kranjske; ta naslova sta ostala v rokah družine do leta 1335. Bistriški svet zaradi tega ni bil vključen v štajerski deželnoknežji urbar, ki so ga Habsburžani dali sestaviti okoli leta 1290. (Slovenska) Bistrica je bila torej enako kot Savnija zastavljena Tirolsko-Goriškim skupaj s Kranjsko, in šele od leta 1311, ko - kot eden od rezultatov boja za češko dediščino Henrik Tirolski odstopi tako Bistrico kot Savnijo Habsburžanom (Bele 2018, 37), je Bistrica dokončno postala del dežele Štajerske (Niederstätter 2001, 289). Ravno v t. i. »tirolski« dobi na Bistriškem pa je sledilo tudi formalno povzdignjenje trga Bistrica v mesto. Leta 1309 je v Štajerski rimani kroniki prvič označena kot mesto, leta 1310 je žička listina, sestavljena v Bistrici, pečatena s "sigillo vniuersitatis burgensium in Feusteriz" (pečat mesta Bistrice je bil sicer prvič uporabljen vsaj že leta 1297, ko z mestnim pečatom potrdijo podelitev bistriškega meščana Frizolda nunam v Studenicam; vendar je pečat s te listine izgubljen), leto kasneje je kraj imenovan kot »oppidum « in nato leta 1313 ponovno kot mesto (Weiss 2002, zbirka listin). Listina iz leta 1297 pa dokazuje, da je že konec 13. stoletja Bistrica dosegla stopnjo avtonomije, za katero so značilni mestnik sodnik in skupnost meščanov, ki upravljajo mesto. Poleg Frizolda se namreč omenja v listini tudi »Wolcmar richer ze Veustirtz« ter še vsaj trije drugi meščani (Otorepec 1988, 186). Tudi omemba iz leta 1311 pa kljub uporabi izraza oppidum (trg) govori o mestu, saj so v listini našteti Štefan "civis in Veustritz« in meščana Holzappfel in Stanislav, oba nedvomno označena kot »cives«, se pravi meščana, »dicto oppido«, imenovanega trga. Pojma civi(ta)s in oppido je pisar očitno uporabljal kot enakovredna oz. sopomenska.

Prostor Slovenske Bistrice in z njim tudi mesto sta bila torej vrnjena v okvir štajerske dežele leta 1311. Do tega časa je Bistrico upravljal Konrad Aufensteinski, ki mu je vojvoda Oto Tirolski zastavil omenjeno posest kot nadomestilo za dolg v višini 400 mark. Po ponovnem prehodu Bistrice 
v roke Habsburžanov in Štajerske pa za koroško-tirolskega plemiča ni bilo več prostora. Leta 1313 je bil dolg 400 mark poravnan, zaradi česar je tudi zapadla zastava. Bistrica je bila, kot kaže, nekaj časa upravljana preko glavarjev. Vsaj od leta 1319 dalje je bil tak glavar (hauptmann) Peter iz koroškega Lilienberga (RHSt I, št. 1091). Je pa verjetno napačno predpostaviti, da je Peter Limbarski to službo opravljal vse do leta 1337, kot to domneva Jože Koropec $(1983,100)$. Peter Limbarski je namreč dobil v upravo tudi urad Laško, kjer je bil v dvajsetih in tridesetih letih močno angažiran, medtem ko ga v povezavi s Slovensko Bistrico po letu 1320 (RHSt II, št. 1276a) ne srečamo več (RHSt II, št. 1883; št. 1889; št. 1896). Leta 1335 pa dobijo Bistrico v zastavo gospodje Walseeji in jo obdržijo v svojih rokah do leta 1363. Njim nato sledijo grofje Celjski, ki obdržijo urad v svojih rokah do izumrtja leta 1456. V katerem obdobju je torej mogoče domnevati prihod judov v mesto? Kaj je bil motiv? Ali so bili pobudniki naselitve sami judi ali je bil pobudnik lastnik/zastavni imetnik?

Kot rečeno, je prva omemba, ki dokazuje nedvomno prisotnost judov v Bistrici, šele iz leta 1370. Septembra tega leta je namreč jud iz Bistrice z imenom Haniko s soglasjem žene in dedičev prodal žičkemu samostanu mlin, ki je ležal nad stolpom gospodov iz Majšperka nasproti hiše Tomaža Krajnika in ki mu je pripadel po Nikolaju, sinu Otona. To prodajo tri dni kasneje dodatno potrdi še bistriški meščan Wolfhart, svak starega (bistriškega) župana Jörga, ki proda še svoj delež na omenjenem mlinu (RGJ 3, št. 1316;1317). Prvi po imenu znani bistriški jud, Haniko, je bil sin Menachema, ki je bil leta 1370 že pokojni, vendar za slednjega ne vemo, ali je že bival v Bistrici. Je pa ta predpostavka malo verjetna. Saj se tudi Haniko sam označuje tudi po Mariboru. Leta 1371 nastopa kot priča v listini celjskih judov Chadgima in Muscha, ko skupaj z Abrahamom (oba sta označena kot juda iz Maribora) podpiše listino (RGJ 3, št. 1342). Če je doslej še mogoče ostalo kaj dvoma o upravičenosti enačenja mariborskega in slovenskobistriškega Hanika, pa ta dvom odpade, ko vključimo še listino mariborskega juda Süßmana, izstavljeno 6. avgusta 1374. Süßman je bil namreč sin Jöslina iz Maribora, med judovskimi pričami v navedeni listini pa je naveden tudi »Chanuka«, sin gospoda Menachema (RGJ 3, št. 1442). Se pravi, da je prvi po imenu znani slovenjebistriški jud pravzaprav jud iz Maribora, ki je v Bistrici očitno odprl svojo podružnico ter se, kadar je posloval tam, nazival za juda iz Bistrice, ko pa je posloval v Mariboru, se je predstavljal kot jud iz Maribora. Vendar bi bilo napačno, če bi podlegli 
prvemu vtisu in zaradi tega podatka podcenili vlogo judovske skupnosti v Bistrici. Že nekaj let kasneje je namreč bistriški meščan Kristijan Walch z ženo in otroki prodal žičkemu priorju bratu Konradu, konventu in božji hiši v Žičah svojo posest v velikosti 10 oralov. Posest pa je opisana kot ležeča ob potoku »Scheispach « zraven judovskega pokopališča (RGJ 3, št. 1445). To judovsko pokopališče se omenja v Bistrici še 25. julija leta 1441 (Weiss 2002, zbirka listin) v obširni darilni listini bistriškega župnika Thomasa Säffnerja v korist studeniškega samostana. Obstoj judovskega pokopališča, na podlagi česar Jelinčič Boeta sklepa, da je morala obstajati tudi sinagoga, priča o relativno veliki in predvsem trdno organizirani skupnosti, ki je že leta 1374 torej živela kot taka $(2009,288)$. Poleg omenjenih smemo v 14. stoletje datirati še enega juda iz Bistrice. To je Yeczlein iz Bistrice. Leta 1416 se Jayer, jud iz Maribora, označi kot vnuk Yeczleina iz Bistrice (GZM VI/2); slednji je bil takrat verjetno že pokojni ter o njem, razen tega da je enako kot Haniko tesno povezan z mariborsko skupnostjo, ne vemo veliko. Srečamo ga le še v listini iz leta 1404, ko se skupaj s še večjim številom judov iz Maribora, Ptuja, Mosspacha in Muraua poravna s salzburškim nadškofom Eberhardom. V listini je Ytzel označen kot vojvodov jud iz Bistrice (RGJ 4, št. 2312). V listinskem gradivu najdemo le še enega juda, ki ga lahko povežemo z Bistrico, to je jud z imenom Musch (Moše), ki leta 1427 proda čevljarju Ulriku iz Radvanja vinograd, ležeč »in Glowocziczer perg« pri Pekrah. Musch se v listini označi kot »Ich Muschel jud von Fewstritz, gesessen zue Marchpurg«, se pravi kot jud iz (Slovenske) Bistrice, bivajoč v Mariboru. Pri vseh treh bistriških judih se torej ponovi enaka naveza $z$ Mariborom. Bistriški judje so nedvomno del mariborske judovske skupnosti. judovske listine iz Bistrice nam torej ne omogočajo odgovora na vprašanje, zastavljeno na začetku, o motivu preselitve judov v mesto. Treba bo obrniti perspektivo in pogledati čas ter razmerja, v katerih moremo domnevati prihod judov v Bistrico.

Že ob pregledu zgodbe nastanka in političnega razvoja v Bistrici smo opozorili, da je kraj najverjetneje nastal kot urbana naselbina že leta 1227 in da je bil eden glavnih motivov, ki je vodil deželnega kneza pri povzdigu Bistrice v urbano naselje, konkurenca Ptuju. Vendar Bistrica

2 Koropec $(1983,100)$ domneva, da je Scheispach stranski rokav bistriškega potoka, ki so ga umetno izdelali za potrebe mestne kanalizacije. 
in njeni meščani niso mogli računati na posebno podporo v času, ko sta bila kraj in gospoščina uporabljana za umikanje nezaželenih (Gertruda Babenberška) oz. kot plačilo za usluge (Tirolsko-Goriški grofje). Šele po letu 1335, ko je Bistrica ponovno prišla v roke štajerskih vojvod, Habsburžanov, so se začele stvari spreminjati. In res že leta 1339 Albreht, vojvoda Avstrije, Štajerske in Koroške, izda listino, s katero poda bistriškim meščanom privilegij, po katerem ni bilo dovoljeno tovoriti vina iz Ptuja mimo Bistrice, temveč je moral vsak tovornik tovor razložiti („niderleg«), in nato so ga bistriški meščani tovorili naprej. V privilegiju je ta določba eksplicitno vezana le na ptujsko vino, medtem ko je vino iz (deželnoknežjega) Maribora izvzeto (Weiss 2002, zbirka listin). Ta privilegij je nedvomno neposredno usmerjen proti salzburškemu konkurentu. Napetosti pa se gotovo niso zmanjšale niti po letu 1342, ko pride do sporazuma med Ptujem in Bistrico, po katerem je bilo Ptujčanom dovoljeno, da so tovorili svoje vino skozi Bistrico, so pa zato dobili Bistričani dovoljenje, da so smeli neovirano prodajati svoje blago na ptujskih sejmih in zamenjavati usnje, surove kože, vosek in drugo blago (GZM XIII/1; Koropec 1983, 100). Ali sovpade ta sporazum z imenovanjem Hardegna Ptujskega za bistriškega glavarja, ki je bil tudi razsodnik pri omenjeni poravnavi, lahko le ugibamo. Ne nazadnje Hardegen imenuje vojvodo za svojega gospoda in Ptujski so bili od 13. stoletja dalje štajerski ministeriali. Vsekakor smemo predpostaviti, da se je v tem sporu, kljub podpori Habsburžanov, Ptuj izkazal kot močnejši. Ne glede na to pa ni nobenega dvoma, da je bila podpora Habsburžanov Bistrici povsem jasno izražena. In če se ponovno spomnimo, da je judovska skupnost v Bistrici čez štiri desetletja imela v mestu svoje pokopališče in sinagogo, je povsem jasno, da je moral biti njihov prihod zastavljen zelo ambiciozno in širokopotezno. Zelo težko pa je verjeti, da bi se judje sami lotili tako ambicioznega projekta v relativno majhnem mestu, sploh če še upoštevamo, da so nedaleč stran, v Mariboru, že imeli zelo močno skupnost, ki bi z lahkoto "pokrivala" tudi potrebe v Bistrici. Za to ambicioznostjo je moral stati poleg samega interesa judovske skupnosti še nekdo drug z dovolj moči in interesa, in to je bil lahko samo deželni knez, ki je miniral prizadevanja Ptuja, kjer je le mogel. To povezanost bistriških judov s štajerskimi vojvodami izpričuje tudi že obravnavana oznaka bistriškega juda Itzla kot vojvodovega juda. Zato smemo upravičeno domnevati prihod judov v Bistrico kmalu po letu 1335. Kraj, od koder so prišli, je gotovo Maribor, kjer je bila skupnost tako močna in številna, da je to bilo lahko izvedljivo. Zdi se, da lahko le tako 
pojasnimo presenetljivi podatek o judovskem pokopališču (in obstoju sinagoge) v Bistrici že v sedemdesetih letih 14. stoletja, pojasni pa tudi dejstvo, da so bistriški judje skozi ves čas svojega pojavljanja v dokumentih tesno povezani z mariborsko judovsko skupnostjo (Jelinčič Boeta 2009, 326-327).

Enako povezanost z Mariborom in njegovo judovsko skupnostjo najdemo tudi v Ormožu. Četudi ima kraj v največji meri drugačne okoliščine nastanka oz. razvoja, je mogoče najti v povezavi z judovsko prisotnostjo kar nekaj skupnih značilnosti. Kraj Ormož je nastal na novoosvojeni zemlji, ki so jo v imenu svojega gospoda, salzburškega nadškofa, osvojili do okoli leta 1199 ptujski gospodje (Kos 2005, 335). Friderik III. Ptujski je del posesti prepustil Nemškemu viteškemu redu, nato pa na preostalem delu začel ustvarjati gospostvo Ormož. Tu je poleg na novo zgrajenega gradu nastala tudi urbana naselbina, ki ni obdržala starega imena Holermus, temveč so jo začeli imenovati po ustanovitelju, Friedau. Gospoščino so za Ptujske upravljali njihovi ministeriali, med katerimi izstopata oče in sin Wulfingova, ki se pojavljata v listinskem gradivu med letoma 1299 in 1349 (Blaznik 1988, 33). Naselje ob gradu je preraslo v trško naselbino vsaj do leta 1320, ko se v salzburškem urbarju že imenuje »foro«, se pravi kot trg. Kmalu zatem, leta 1331, mu brata Hardegen in Friderik Ptujska podelita mestne pravice, enake, kot jih je imel sosednji Ptuj. Usoda Ormoža je torej v teh prvih letih povsem povezana s Ptujem, kar dokazuje tudi omemba prvega po imenu znanega ormoškega gorskopravdnega mojstra Hertvika, ki je v urbarju jasno označen kot meščan Ptuja (Kos 1939, 87). Da pa odnosi in povezave niso bili tako enostavni, izhaja iz vloge in položaja Ptujskih. Čeprav je družina prišla na Štajersko v vlogi salzburških ministerialov in se tega statusa formalno niso rešili, je njihov dejanski položaj drugačen. Že v 12. stoletju je družina začela pridobivati krške fevde (Kunšperk, Podsreda), v 13. stoletju so pridobili od madžarskega kralja Bele IV. Borl in Središče ter si v Savinjski dolini pridobili več alodialnih posesti (Kacenštajn, Velenje, Hekenberg), kar jim je omogočilo izvajanje zelo samostojne družinske strategije. Ko pa so podprli Rudolfa Habsburžana in so se povsem integrirali v vrste štajerskih ministerialov, so po njegovi zmagi nad češkim kraljem Otakarjem Přemyslom začeli voditi celo protisalzburško politiko, kar so jim sicer salzburški nadškofje uspeli preprečiti. Kljub temu je njihova moč narasla in omenjeni Hardegen spada v začetku 14. stoletja med najmogočnejše plemiče na Štajerskem (Kos 2005, 354sl.). Ormož so tako upravljali 
kot svoje posestvo in upravičeno je zatrditi, da je Ormož bil in ostal eno glavnih in največjih ptujskih gospostev vse do izumrtja rodbine. Mesto je bilo formalno sicer salzburško, v praksi pa se kot odločilna kaže vloga salzburških fevdnikov Ptujskih.

Če upoštevamo prej opisana prizadevanja Ptujskih za čim večjo osamosvojitev iz fevdnih vezi, je seveda mnogo razumljivejše, zakaj v Ormož ne pridejo judje, povezani s salzburškim Ptujem, temveč z deželnoknežjim Mariborom. Trditev je sicer morda nekoliko nenavadna in jo je zato treba natančneje razložiti. Prvič izvemo za juda iz Ormoža leta 1340, ko se pri judu Iserleinu iz Ormoža zadolži za 73 goldinarjev Neža, vdova po Gotfridu IV. Mariborskem. Kot porok pa je naveden Gotfridov sorodnik Henrik IV. iz Viltuša (RGJ 2, št. 479). Povsem pravilna je ugotovitev, da je Iserlein, ki se kot ormoški navaja samo v tej listini, najverjetneje identičen $z$ Iserleinom, ki se imenuje tudi po Ptuju in po Mariboru. Tako je leta 1350 potrdil, da mu je Gotfrid V. Mariborski vrnil dolg v znesku 200 goldinarjev (RGJ 2, št. 652), novembra 1350 pa se isti Iserlein že imenuje kot jud iz Maribora (RGJ 2, št. 669) in nato to oznako obdrži do svoje smrti. ${ }^{3}$ Opravka imamo torej z judom, ki je svoje posle vodil tako s Ptuja kot iz Maribora, vsaj krajši čas pa tudi iz Ormoža. Ne glede na to so bili njegovi posli še v času, ko je deloval na Ptuju, povsem nepovezani s salzburškim nadškofom. Njegove stranke so tako poleg mariborskih plemičev še opatija Gornji Grad ter Celjski grofje (RGJ 2, št. 510; št. 541). Po letu 1350 pa je ta njegova usmeritev v deželnoknežje plemstvo še izrazitejša.

Vsekakor Iserleina ne moremo šteti med salzburške jude. V njegovem delovanju ter v delovanju njegovih sinov moremo videti izrazito samostojno družinsko politiko, ki pa je svoj interes očitno videla predvsem v krogu deželnega plemstva. Zato ga tudi pogojno obravnavamo kot deželnoknežjega, in ne salzburškega juda. Gospodje Ptujski, kot gospodje mesta Ormož, so očitno spodbujali kontakte, ki so kraj trgali od morebitnih salzburških povezav, in so tako verjetno dali pobudo, da v Ormož pride judovska družina, ki s Ptujem ni pretesno povezana. Iserlein je sicer v Ormožu deloval relativno kratek čas. Pa tudi sicer je bila judovska prisotnost v Ormožu zelo kratke sape. Kljub privlačni legi kraja ob meji in ob eni najprometnejših 
srednjeveških cest mesto v konkurenci s salzburškim Ptujem in deželnoknežjo Radgono ni imelo ravno veliko možnosti za razvoj. V Ormožu tako poznamo samo še dve, kot kaže, med seboj nepovezani listini ormoških judov. 21. novembra 1352 se Mihael iz Radgone skupaj s svojim zetom Zirvasom zadolži za 60 goldinarjev pri ormoškem judu Henleinu (RGJ 2, št. 726). Vsekakor pa že relativno nizka višina dolga ter dejstvo, da gre za posojo meščanom, in ne plemičem, pričata o relativno skromnem obsegu delovanja omenjenega juda. Tretja in zadnja listina, kjer se omenja ormoški jud/judinja, pa je iz leta 1362, ko je avstrijski, štajerski in koroški vojvoda Rudolf potrdil, da je njegov zvesti Nikolaj, grof iz Halbenraina, poravnal svoj dolg v višini 360 goldinarjev, ki ga je imel do ormoške judinje z imenom Golda (RGJ 2, št. 281). Delovanje slednje je bilo očitno mnogo bolj ambiciozno kot Henleinovo pa tudi Iserleinovo pred njim, vendar o njej ne vemo nič več. judinja s tem imenom se omenja le še v Beljaku leta 1347, ko se omenja kot mati Velkleina in Slamana. Zgolj z veliko mero previdnosti bi lahko v ormoški Goldi videli hčer beljaške, je pa predpostavka komaj verjetna, saj ni jasna povezava judovske rodbine iz bamberške Koroške z vzhodno Štajersko. Žal moramo torej zaključiti, da o tej zelo zanimivi osebnosti ne vemo ničesar. S to omembo pa se tudi zaključi omenjanje judov v Ormožu. Najbrž so se iz kraja tudi relativno kmalu umaknili - konkurenca in ne nazadnje privlačnost sosednjih, večjih in pomembnejših mest je bila vendar premočna. Kljub temu pa smemo ugotoviti, da je bil poskus naseliti jude v Ormožu vsaj spodbujen s strani Ptujskih gospodov, ki so se pri tem zavestno izognili preveliki povezavi s salzburškim Ptujem. Manj izrazito, pa vendar do neke mere podobno protisalzburško ravnanje je torej vidno tudi pri t. i. judovski politiki.

\section{Slovenj Gradec in Dravograd}

$\mathrm{V}$ drugem delu razprave bomo fokus premestili na vzhodni rob slovenskoštajerske dežele, k mestu Slovenj Gradec (ter tudi trgu Dravograd), ki je v času, ki ga bomo obravnavali, še vedno del dežele Koroške, je pa postajal (kar se bo videlo tudi skozi obravnavo slovenjgraških judov) vedno bolj del štajerske zgodbe. Oprli se bomo predvsem na avtorjevo pred kratkim 
izdano monografijo, posvečeno temu kraju. Uvodna predstavitev je tako v celoti povzeta iz nje (Ravnikar 2018). ${ }^{4}$

V Slovenj Gradcu zgradijo na temeljih nekdanjega gradišča, ki je gotovo opravljalo centralno upravno, vojaško in sodno vlogo, do 11. stoletja prvi srednjeveški grad, ki pa ohrani še naprej oznako gradišče/gradec. Pod tem imenom se ta grad v virih posredno prvič leta 1091 imenuje kot "Grez«, ko se tudi razkrijejo domnevno prvi fevdalni posestniki v Mislinjski dolini. Po Gradcu se namreč naziva eden najpomembnejših plemičev širše vzhodnoalpskega prostora, grof Werigand, ki spada v širši krog naslednikov rodu Heme in savinjskega mejnega grofa Viljema II., tako imenovanih Askvinov, oz. kot so na Slovenskem bolj poznani, grofov Višnjegorskih. Werigand je v času boja za investituro med drugim izgubil večino svojih posesti v Dravski in Mislinjski dolini v korist zmagovitega grofa Bernarda Spanheima. Toda čas gospostva Bernarda Spanheima je trajal le kratek čas, saj je s preostalo Bernardovo dediščino tudi Mislinjska dolina prešla v roke Otokarja III. Traungavca, štajerskega mejnega grofa, ki pa to posest prav tako zelo hitro izgubi. Vsaj leta 1174 so gospodje Slovenjgraškega grofje Andeški. Z njimi pa se začne prvo zlato obdobje tako doline kot v prvi vrsti kraja. Verjetno je kmalu po začetku gospodovanja Andeških prišlo tudi do prenosa naselbine iz starega prostora v Starem trgu na novo lego, kjer so Andeški načrtno zgradili mestno naselbino.

V zadnji četrtini 12. stoletja, se pravi v času gospostva Andeških, pa v kraju začne delovati tudi kovnica denarja. Na sploh se v virih kraj vedno bolj kaže kot izgrajen urbani center $z$ urejenim trgovanjem, normiranim pobiranjem davkov itd. in ga moramo prištevati med urbane naselbine. V tem obdobju lahko prvič v virih zasledimo še eno lastnost Slovenjgraškega, ki jo kasnejši viri nato še jasneje dokumentirajo. Dolina leži geografsko na meji med Koroško in Štajersko oz. historično Kranjsko, in grofje Andeški to svojo posest obravnavajo kot posebno entiteto, ki je ne prištevajo ne k svojim kranjskim posestim ne h Koroški. Ta posebna lega Slovenjgraškega znotraj andeških posesti se kaže tudi v izgradnji in obstoju relativno tesno povezane andeške ministerialitete, katere pripadnike lahko poimensko ravno

4 Posebej poglavji: Slovenj Gradec v drugi polovici 13. stoletja (34-47) in Slovenj Gradec v času Konrada Aufensteinskega (48-63). 
v tem času spoznamo in jih nato spremljamo. Čas prve polovice 13. stoletja, se pravi čas Andeških, upravičeno velja za zlato dobo mesta. Henrik IV. Andeški ter nato njegov brat oglejski patriarh Bertold V. sta se večkrat izpričano nahajala v Slovenj Gradcu, tu listinila ter kraj tako gospodarsko kot sicer intenzivno podpirala. V letu 1251, ob patriarhovem zadnjem obisku Slovenj Gradca, ko je v mestu posvetil cerkev sv. Elizabete, je bilo natančneje popisano, kaj vse je spadalo $\mathrm{k}$ patriarhovim posestim $\mathrm{v}$ provinci Slovenj Gradec: vse, kar ima patriarh v provinci, na gradu ter v trgu z vsemi sodnimi pravicami, mitnino ter kovnico denarja ter vsa ministerialiteta in podložniki. Patriarh pa še prav posebej poudari, da velja za ministeriale in kastelane na Slovenjgraškem ministerialno pravo oglejske cerkve, po katerem se ravnajo. Ponovno pride do izraza posebni status slovenjgraške pokrajine, ki ga v drugi polovici 13. stoletja še dodatno podkrepi obstoj posebnega vicedoma za Slovenjgraško (Ravnikar 2018, 45).

Z omenjeno listino iz leta 1251 je patriarh vse svoje posesti prepustil oglejski cerkvi, ki pa te pravice v praksi skoraj ni mogla uveljavljati. Prostor je bil preveč privlačen in pomemben, da bi lahko ušel zanimanju mogočnih magnatov iz sosedstva. Tako je koroški vojvoda Ulrik III. Spanheim izkoristil situacijo in se polastil Slovenjgraškega ter kraju takoj tudi še formalno podelil mestne pravice, ki pa jih je kraj v praksi imel že kar nekaj časa. Mesto je nato zelo hitro dobilo tudi obzidje, ključni pokazatelj mestnosti naselja. Obzidje je postalo bistveni element mestnega pečata, ki je z dobrimi argumenti datiran v tretjo četrtino 13. stoletja, se pravi, da si je mesto, takoj ko je formalno dobilo potrjene mestne pravice, dalo izdelati mestni pečat, s katerim so se lahko predstavljali tudi navzven. Ulrik Spanheimski je Slovenj Gradec zelo hitro vključil v sam center svoje dinastične politike, vendar so njegovi načrti leta 1269 umrli skupaj z njim, mesto pa je v enem letu postalo last novega koroškega vojvode in gospoda Kranjske, češkega kralja Otokarja II. Přemysla. Tudi on je nadaljeval politiko svojega bratranca Ulrika ter je Slovenjgraško obravnaval in upravljal kot posebno pokrajino. Ulrik iz Haßbacha je bil tako s strani Otokarja imenovan za glavarja Kranjske, (Slovenske) Marke in Slovenjgraškega, pokrajino je upravljal ne več koroški, temveč kranjski glavar, vendar je ostala posebna upravna enota. $\mathrm{V}$ mestu še vedno deluje kovnica denarja in mesto kljub vsem relativno hitrim političnim spremembam prosperira. To stanje se ne spremeni niti po porazu in smrti češkega kralja v spopadu z nemškim kraljem Rudolfom Habsburžanom. Mesto uspe zaradi prerivanj med velikimi magnati za krajši 
čas ponovno dobiti pod nadzor oglejski patriarh. V poravnalnih procesih zaradi posameznih sporov, katerih listine so ohranjene $\mathrm{v}$ furlanskih arhivih, pa najdemo naštete tudi prve meščane in njihove dejavnosti. Poleg običajnih in pričakovanih dejavnosti (mesar, sodar ipd.) najdemo naštete tudi obrtnike, ki se ukvarjajo z bolj specifičnimi dejavnostmi (izdelovalec tunik, morda izdelovalec samostrelov, čeprav je enako verjetno, da gre za strelca, vojaka, v slovenjgraški trdnjavi, ipd.), kar priča o zelo razvejeni, pisani sliki obrtnikov, ki bivajo in delujejo v mestu. Še vedno pa lahko spremljamo zelo (lokalno, pa vendar) vplivno ministerialno skupnost, ki se vedno znova pojavlja v listinah (Ravnikar 2018a, 55-78).

Poraz Otokarja II. Přemysla oz. zmaga Rudolfa Habsburžana prinese ponovne spremembe pri upravitelju mesta. Rudolf namreč Slovenj Gradec (skupaj s Koroško in Kranjsko) preda v fevd oz. zakup svojemu glavnemu zavezniku, Majnhardu II. Tirolskemu, skupaj s Tirolci pa na Slovenjgraško pride Konrad Aufenstein, ena najpomembnejših osebnosti v srednjeveški zgodovini mesta. Vse do smrti koroškega vojvode Henrika Tirolskega leta 1335 je Konrad Aufenstein v mestu predstavljal absolutno avtoriteto ter si zgradil pravi dinastični teritorij od Železne Kaple do Slovenj Gradca. V prvih letih gospodovanja Tirolcev pridejo v mesto tudi predstavniki zelo vplivne bankirske družine iz Firenc Frescobaldiji ter odprejo v mestu svojo podružnico. Ta je zaradi mnogih okoliščin delovala v mestu le kratek čas, pa vendar njena prisotnost kaže, da se je mesto od začetkov na prelomu iz 12. v 13. stoletje razvilo v središče nadregionalnega pomena (Kosi 2008, 158sl.).

Slovenj Gradec znotraj tega aufensteinskega imperija predstavlja najpomembnejše urbano, se pravi gospodarsko in upravno središče. Toda Konrad še ni bil zadovoljen z dotedanjimi koraki. Da bi si dodatno utrdil finančni položaj, je v Slovenj Gradec, „glavno mesto svoje dežele«, poklical tudi jude. Prisotnost judovske družine v Slovenj Gradcu namreč prvič zabeležimo ravno v času aufensteinskega upravljanja. V slovenjgraškem gradivu iz obdobja med 1334 in 1338 najdemo tako 12 listin, ki jih je ali izstavil ali bil v njih omenjen slovenjgraški jud z imenom Moša (Musch). (Jelinčič Boeta 2009, 236-237) Njegovi posli so vedno povezani s plemstvom iz samega Slovenj Gradca oz. iz neposredne okolice. Tako je že v prvi znani listini 
s 30. januarja leta 1334 dal posojilo Hermanu, sinu Hermana iz Staudacha. ${ }^{5}$ Kot poroki posojila pa so bili določeni Oto iz Šentlovrenca, njegov svak Matias in "Fritz«, sin Friderika iz Slovenj Gradca. Kot priče se podpišejo brata Ortolf in Friderik iz Slovenj Gradca, Hans »der Chuenmaister" in judje Aron, Judas in Haneko. (RGJ 1, št. 371) Že ta prva listina izkazuje značilnost, ki jo je Wilhelm Wadl poimenoval za starejši tip zadolžnega pisma, v katerem listino potrdijo tako s pečatenjem kot $z$ daljšo vrsto prič, enakomerno krščanskih in judovskih (Wadl 1992, 155). Aron, ki je bil priča izstavitvi obravnavane listine, se pojavlja v listinah slovenjgraškega Moše še osemkrat, zato je upravičena domneva, da je tudi on živel v Slovenj Gradcu. Enako velja tudi za Judasa, ki v Moševih listinah nastopa kot priča petkrat. Jud Haneko pa je gotovo identičen z velikovškim judom Haneko (RGJ 1, št. 289 /1328, 25. februar/).

Še v istem letu lahko poimenski seznam slovenjgraških judov oz. kroga, iz katerega izhajajo, še nekoliko razširimo. 1. novembra 1334 so se namreč pri Moši iz Slovenj Gradca zadolžili Bertold Kropf, Herman Plötzler in Lienhard iz Slovenj Gradca, vsi trije pripadniki lokalnega viteštva (RGJ 1, št. $383 / 1334$, 1. november/). Judovski tekst ob robu listine ta dolg še specificira. Pravi namreč, da je (Bertold) Kropf dolžan 3 marke srebrne teže, medtem ko sta (Herman) Plötzler in Lienhart iz Slovenj Gradca poroka. Dolg pa naj bi bil vrnjen do sv. Jurija, in če ne bo, se poroki zavežejo k obstagiju, vse dokler ne bo dolg vrnjen skupaj z obrestmi. V listini so med judovskimi pričami našteti Aron, Tovi in Haneka. Novo ime, ki se pojavlja, je Tovi, ki ga upravičeno lahko enačimo s celovškim judom Tovije, ki se v listinah pojavlja od leta 1325. Značilno pa je tudi, da tega Tovija najdemo kot pričo v listini, s katero je Konrad Aufensteinski poravnal svoj dolg do Nachmana, juda iz Brež. (RGJ 1, št. 368 /1333, 18. november, Velikovec/) Morebiti bi lahko domnevali, da je bil Tovi že takrat v navezavi z Aufensteinskim ravno preko Slovenj Gradca oz. da Tovi že biva v Slovenj Gradcu.

5 Družina sicer izhaja iz Koroške, z gradu Wilaren oz. imenovanega tudi Staudachhof pri Brežah. Leta 1306 se v listinah prvič pojavi Herman Staudach, ki velja za začetnika novega rodu, živečega na tem gradu. Srečamo ga že v prvi listini, v kateri se pojavi prisoten na gradu Slovenj Gradec, kjer priča v listini Konrada Aufensteinskega (Pettenegg, Urkundenbuch, XXI). Sicer so bili Staudachi krški ministeriali in domneva se, da naj bi v tej vlogi Herman tudi prišel v krško Vitanje (Wiessner 1977, 134-135). Ravno listina iz leta 1306 pa kaže na tesno povezavo tudi med Staudachi in Aufensteini, tako da bi morda lahko tudi tako razložili prihod Staudachov v Mislinjsko dolino. 
Novembra 1336 je Moša razglasil, da sta Konrad iz Aufensteina in njegova žena Diemuta pri njem brez dolgov, kar potrdita s svojima pečatoma tako novi zastavni gospod Slovenjgraškega, krški škof Lovrenc, kot tudi samo mesto, katerega pečat je bil prav tako obešen na listino (RGJ 1, št. 406 /1336, 11. november/). Dejanje lahko razumemo kot eno ključnih pri predaji Slovenjgraškega iz rok Konrada Aufensteinskega v roke krškega škofa. Škof pa je še naprej podpiral prisotnost judov v mestu, saj se je očitno več kot zavedal njihove koristi za gospodarski razcvet. Moša tako v mestu še naprej biva in deluje. Je pa njegov krog še vedno povezan povsem lokalno in je temu primerno tudi treba ocenjevati obseg in domet njegovega delovanja (RGJ I, št. 417; št. 423; št. 431; št. 432; št. 433; št. 437).

Ravno navedene judovske listine pa prinašajo še en podatek. V vsaki od njih je ob koncu zapisano, da bo v primeru neplačila glavar Slovenjgraškega ali pa koroški glavar poskrbel za to, da se dolg vrne. Slovenjgraško je torej še vedno imelo svojega glavarja, svojo upravo ločeno tako od Koroške kot od Štajerske, je pa bilo v času krškega gospostva vendarle kot posebna enota priključeno h Koroški. Tako namreč lahko razložimo, da sta bila zadnji instanci, h kateri se je lahko po pomoč obrnil posojilodajalec, glavar v Slovenj Gradcu in (ali) glavar na Koroškem.

Moša, jud iz Slovenj Gradca, se v gradivu pojavi torej še leta 1338, ko 22. aprila izda kar tri listine, s katerimi določijo dolgove Konrada Kranbergerja (iz Dravograda), Lovrenca iz Guštanja in Mateja iz Pliberka. Lovrenc iz Guštanja se pri judih še dodatno zadolži maja istega leta, nato pa viri obmolknejo. Domnevamo lahko, da se je judovska družina okoli leta 1340 s Slovenjgraškega umaknila. Ali je bil razlog smrt Moše in nezainteresiranost njegovih naslednikov za delovanje v verjetno relativno slabo donosnem poslu v Slovenj Gradcu ali pa kaj drugega, lahko le ugibamo. Poudariti pa je treba, da so ti judje prišli v mesto s posredovanjem Konrada Aufensteinskega in da jih je pripeljal iz koroškega prostora, kjer se je z družino tudi srečal. Ko se v mestu nato čez približno 30 let znova pojavijo judje, to niso več pripadniki iste družine, temveč so to judje, ki na Slovenjgraško pridejo iz Celja in pripadajo mogočni judovski skupnosti, ki deluje med Mariborom, Slovensko Bistrico in Celjem, njihove povezave pa segajo vse do Dunajskega Novega Mesta. (Jelinčič Boeta 2009, 237.261-283) 
Leta 1364 je vojvoda Rudolf za 1300 funtov zastavil Slovenj Gradec Kolonu Vuzeniškemu. Skupaj z Vuzeniškimi se v prostor Mislinjske doline vrnejo tudi judje. Toda pri prej obravnavani listini iz leta 1364, v kateri je Konrad Staudach priznal svoje dolgove do judov Hačima in Avigdorja, je verjetno, da slednja še nista rezidirala v Slovenj Gradcu, čeprav so poroštvo za dolg prevzeli nase sami Slovenjgradčani: šmarški župnik Markvard, Henrik Hebestreit in Nikolaj Paver (iz Guštanja). Drugače pa je v desetletju med 1378 in 1388, ko se neka judovska družina ponovno imenuje po Slovenj Gradcu in v mestu nedvomno živi. Glede na osebna imena, ki se v tej družini pojavljajo, Nachim in Moša, ter glede na to, da se gibljeta v istem krogu kot celjsko-mariborska judovska družina, v kateri najdemo isti dve osebni imeni, ne more biti dvoma, da je družina celjskih/mariborskih judov razširila svoje poslovanje tudi v Slovenj Gradec. Kot rečeno, pa je njihova prisotnost relativno kratke sape, zadnjič jih najdemo omenjene decembra leta 1388, ko Nachim iz Slovenj Gradca potrjuje dolg celjskih grofov Viljema in Hermana I. (Weiss, CD rom, 1388, 7. december) Je pa dejavnost te družine razširjena na mnogo širši prostor, kot smo to lahko opazovali pri prvi slovenjgraški judovski družini. Med njihovimi dolžniki najdemo celjske grofe in Huga Devinskega, od leta 1374 zastavnega imetnika Slovenj Gradca (RGJ 3, št. 1563; št. 1570; št. 1727; št.1793).

Pred zaključkom in rekapitulacijo pa samo še skok v nekoliko nenavadno pojavljanje judov v trgu Dravograd. Dravograd je nastal na pomembnem prometnem križišču, kjer so štajerski ministeriali gospodje Trušenjski okrog leta 1160 nelegalno postavili grad in trg s cerkvijo ter mostom čez Dravo. Naselbina je že od samega začetka imela neagrarni značaj, saj se v poravnavi, sklenjeni med letoma 1180 in 1192, že omenjajo mitnina in druge tržne terjatve, vezane na ta trg (GZS 4, 639; Kosi 2009, 120s). Kosi pravilno sklepa, da je do ustanovitve trga prišlo na pobudo štajerskih mejnih grofov, ki so okoli leta 1170 izgubili svojo posest Slovenj Gradec in postavili konkurenčni trg $\mathrm{v}$ soseščini. Ne glede na štajersko iniciativo pri ustanovitvi pa je bil Dravograd trušenjska ustanova in se kot tak tudi imenuje leta 1237. (GZS 4, 667; Kosi 2009, 121) Dravograd je bil torej ministerialna ustanova, ki se v nadaljevanju sicer ni mogla enakopravno meriti s sosednjim Slovenj Gradcem, kljub temu pa je bila dovolj privlačna za različne tipe prebivalstva, da so se naseljevali v njej. In med njimi so bili tudi judje. Njihova prisotnost je zabeležena le enkrat, ko se v letu 1388 imenujeta kot dravograjska juda brata Ysserl in David, sinova Aroma, 
juda iz Dravograda, ki sta posodila 130 goldinarjev Guštanjčanu Nikolaju Paverju in njegovi ženi Ani (Wadl 1992, 157). Šlo je za povsem lokalno finančno transakcijo, ki ne omogoča sklepanja o obširnejši in ambicioznejši dejavnosti obeh bratov. Kot zanimivost pa še to, da je listino pečatil sodnik za jude iz Gradca, in ne iz Maribora, ki bi bil predvsem geografsko bližji in primernejši. Jelinčič Boeta na podlagi te listine sklepa, da ne moremo predvidevati judovske prisotnosti v Dravogradu, daljše od okoli deset let. Sklep je povsem logičen, je pa bila zavezanost Dravogradu pri bratih vendarle večja, kot bi bilo mogoče sklepati po predvidoma kratkem času bivanja. Ysserleina najdemo omenjenega le v navedeni listini, drugače pa je z Davidom. Ta se je iz Dravograda preselil na Dunaj, kjer ga je mogoče najti v kar 55 listinah, vedno navedenega kot »iz Dravograda«. (Jelinčič Boeta 2009, 236; Wadl 1992, 157) Se pravi, da je do konca ohranil svojo koroško, dravograjsko identiteto, kar pa vendar govori o močnejših dravograjskih koreninah, kot bi bilo sicer mogoče sklepati. Posledično pa to dejstvo izpričuje, da je morala biti judovska prisotnost v Dravogradu vendarle daljša in predvsem intenzivnejša, kot to izpričujejo ohranjeni viri.

\section{Namesto zaključka}

Če potegnemo črto. V uvodu v razpravo smo si zadali nalogo odgovoriti na nekaj ključnih vprašanj, vezanih predvsem na čas in vzrok prihoda judov v posamezne spodnještajerske urbane kraje. Kot vzorčne primere smo tako izbrali manjše kraje, kjer je judovska navzočnost zabeležena v dokumentih. Na kratko moremo zaključiti, da se vloga deželnih gospodov, predvsem Habsburžanov, kaže kot ključna pri spodbujanju in podpiranju judov pri odločitvi, da se naselijo v določenem kraju. To se verjetno najbolj jasno vidi pri različnih zgodbah dveh mejnih mestec, Ormoža in Brežic. Obe mesti sta tesno vezani na salzburškega nadškofa, toda če se je Ormož predvsem zaradi samosvoje politike družine Ptujskih in njihove naslonitve na štajerske vojvode tesne zveze s Salzburgom v veliki meri otresel, je ta podreditev oz. salzburška nadvlada ostala v Brežicah zelo izrazita (Ravnikar 2011, 250sl.). Posledično v Ormožu pride do poskusa (sicer relativno kratkotrajnega, pa vendar) nastanka ormoške judovske skupnosti, medtem ko v Brežicah ni o čem podobnem ne duha ne sluha. 
Verjetno še jasnejši angažma štajerskih vojvod je videti tudi pri primeru Slovenske Bistrice, kjer je očitno, da je ravno njihov interes tisti, ki je ne samo omogočil prihod judov v mesto, temveč v veliki meri tudi uravnaval njihovo delovanje.

Tudi primer Slovenj Gradca kaže na podoben vzorec. Tudi tu je za prihod judov v mesto odločilen vpliv deželnega gospoda, le da je ta v tem primeru izražen posredno, skozi delovanje deželnoministerialne družine Aufensteinov, ki pa je bilo brez dvoma povsem usklajeno z željami njihovega gospoda, koroškega vojvode. Iz celotne slike še najbolj izstopa primer Dravograda, kjer pa imamo nenavaden moment, ko se, kot kaže, štajerski judje (vsaj tako kaže dejstvo, da se podredijo sodniku za jude iz Gradca) naselijo v kraju. Ravno primer Dravograda tudi kaže, kako majhno količino podatkov imamo na razpolago, saj ni jasen niti čas prihoda in s tem njegova dolgotrajnost niti povezava dravograjskih judov z morebitnimi skupnostmi iz koroškega oz. štajerskega prostora. Usoda juda Davida iz Dravograda na Dunaju kaže le na to, da je bila njegova povezanost z matičnim (?) Dravogradom zelo velika in je morala presegati kratkotrajno navzočnost. Vsekakor pa je mogoče zaključiti ne samo, da je bila vloga deželnih gospodov (pričakovano) tista, ki je v največji meri krojila prisotnost oz. neprisotnost judov po posameznih krajih, temveč tudi to, da je še prav posebej izpostavljena vloga Habsburžanov (in Tirolskih kot koroških vojvod) kot štajerskih deželnih gospodov. Različna pristopa $\mathrm{k}$ (ne)prisotnosti judov lahko vidimo skozi primerjavo salzburških Brežic, kjer jude zaman iščemo, in prav tako salzburškega Ormoža, kjer so zaradi izpostavljene vloge Ptujskih gospodov prisotni v 14. stoletju. Poudarjeno vlogo Habsburžanov pa nam prinaša tudi analiza gradiva mesta Slovenska Bistrica. Vsekakor pa bo za več odgovorov tej analizi treba dodati še podobno za kranjsko deželo in za prostor Goriške in Istre. 


\section{Kratice}

GZM VI Mlinarič 1980 [Gradivo za zgodovino Maribora, zv. 6].

GZM XIII Mlinarič 1987 [Gradivo za zgodovino Maribora, zv. 13].

GZS 4 Kos 1915 [Gradivo za zgodovino Slovencev v srednjem veku, zv. 4].

GZS 5 Kos 1928 [Gradivo za zgodovino Slovencev v srednjem veku, zv. 5].

RGJ 1 Brugger in Wiedl 2005 [Regesten zur Geschichte der Juden in Österreich im Mittelalter, zv. 1].

RGJ 2 Brugger in Wiedl 2010 [Regesten zur Geschichte der Juden in Österreich im Mittelalter, zv. 2].

RGJ3 Brugger in Wiedl 2015 [Regesten zur Geschichte der Juden in Österreich im Mittelalter, zv. 3].

RGJ4 Brugger in Wiedl 2018 [Regesten zur Geschichte der Juden in Österreich im Mittelalter, zv. 4].

RHSt I Redik 1976 [Regesten des Herzogtums Steiermark, zv. 1].

RHSt II Redik 2008 [Regesten des Herzogtums Steiermark, zv. 2].

StUB III Von Zahn 1903 [Urkundenbuch des herzogthums Steiermark, zv. 3].

\section{Reference}

Bele Martin. 2018. Pogumni vojaki in zviti politiki. Boji in spletke spodnještajerskih plemičev v 13. stoletju. Maribor: Znanstvenoraziskovalni inštitut dr. Frana Kovačiča.

Blaznik, Pavle. 1988. Historična topografija Slovenije II: Slovenska Štajerska in jugoslovanski del Koroške do leta 1500. Zv. $2 N-Z ̌$. Maribor: Založba Obzorja.

Brugger, Eveline, in Birgit Wiedl, ur. 2005. Regesten zur Geschichte der Juden in Österreich im Mittelalter. Zv. 1 Von den Anfängen bis 1338. Dunaj: Studien Verlag.

- - -. 2010. Regesten zur Geschichte der Juden in Österreich im Mittelalter. Zv. 2 1339-1365. Dunaj: Studien Verlag.

- - -. 2015. Regesten zur Geschichte der Juden in Österreich im Mittelalter. Zv. 3 1366-1386. Dunaj: Studien Verlag.

- - -. 2018. Regesten zur Geschichte der Juden in Österreich im Mittelalter. Zv. 4 1387-1404. Dunaj: Studien Verlag.

Dopsch, Heinz. 1999. Die Länder und das Reich. V: Österreichische Geschichte 1122-1278. Dunaj: Carl Ueberreuter Verlag.

Jelinčič Boeta, Klemen. 2009. Judje na Slovenskem v srednjem veku. Ljubljana: Slovenska matica.
Koropec, Jože. 1957. Slovenjebistriški svet v luči prvih deželnoknežjih urbarjev. Kronika: časopis za slovensko krajevno zgodovino 5/1: 20-25.

- - -. 1983. Svet okoli Slovenske Bistrice do leta 1700. V: Zbornik občine Slovenska Bistrica I. Slovenska Bistrica: Skupščina občine in Kulturna skupnost občine Slovenska Bistrica.

Kos, Dušan. 2005. Vitez in grad: Vloga gradov v življenju plemstva na Kranjskem, slovenskem Štajerskem in slovenskem Koroškem do začetka 15. stoletja. Ljubljana: Zveza zgodovinskih društev Slovenije.

Kos, Franc, ur. 1915. Gradivo za zgodovino Slovencev v srednjem veku. Zv. 41101 1200. Ljubljana: Leonova družba.

Kos, Milko, ur. 1928. Gradivo za zgodovino Slovencev v srednjem veku. Zv. 5 12011246. Ljubljana: Leonova družba.

- - -. 1939. Srednjeveški urbarji za Slovenijo 1: Urbarji salzburške nadškofije. Ljubljana: Katoliško tiskovno društvo.

Kosi, Miha. 1998. Potujoči srednji vek: Ceste, popotnik in promet na Slovenskem med antiko in 16. stoletjem. Ljubljana: Zveza zgodovinskih društev Slovenije.

Mlinarič, Jože, ur. 1980. Gradivo za zgodovino Maribora. Zv. 6 1416-1445. Maribor: Pokrajinski arhiv Maribor. 
- - -. 1987. Gradivo za zgodovino Maribora. Zv. 13 Dokumenti iz Mariborske mestne knjige I 1342-1737. Maribor: Pokrajinski arhiv Maribor.

- - -. 1991. Kartuziji Žiče in Jurklošter. Maribor: Arhivsko društvo Slovenije.

- - -. 2000. Judje na Štajerskem do njihove prisilne izselitve v letu 1946. Casopis za zgodovino in narodopisje 71/1-2: 49-70.

Niederstätter, Alois. 2001. Die Herrschaft Österreich. V: Österreichische Geschichte 1278-141. Wien: Carl Ueberreuter Verlag.

Otorepec, Božo. 1988. Srednjeveški pečati in grbi mest in trgov na Slovenskem. Ljubljana: Zveza zgodovinskih društev Slovenije.

Pirchegger, Hans. 1962. Die Untersteiermark in der Geschichte ihrer Herrschaften und Gülten, Städte und Märkte. München: Oldenbourg.

Ravnikar, Tone. 2011. Mestne elite v srednjeveških Brežicah in Sevnici. V: Janez Mlinar in Bojan Balkovec, ur. Mestne elite $v$ srednjem in zgodnjem novem veku med Alpami, Jadranom in Panonsko nižino. Zbirka Zgodovinskega časopisa 42. Ljubljana: Zveza zgodovinskih društev Slovenije.
- - -. 2018. Slovenj Gradec v srednjem veku. Maribor: Znanstvenoraziskovalni inštitut dr. Franca Kovačiča.

Ravnikar, Tone in Aleš Maver. 2018. Mestno plemstvo v Slovenj Gradcu med 13. in 15. stoletjem. Acta Histriae 26/1: 55-78.

Redik, Annelies, ur. 1976. Regesten des Herzogtums Steiermark. Zv. $11308-$ 1319. Gradec: HLK.

- - -. 2008. Regesten des Herzogtums Steiermark. Zv. 2 1320-1330. Gradec: HLK.

Travner, Vladimir. 1935. Mariborski ghetto. Kronika 2, 154-159.

Valenčič, Vlado. 1992. Židje v preteklosti Ljubljane. Ljubljana: Park.

Von Zahn, Joseph, ur. 1903. Urkundenbuch des herzogthums Steiermark. Zv. 3 1246-1260. Gradec: Verlag des Historischen Vereines für Steiermark.

Wadl, Wilhelm. 1992. Geschichte der Juden in Kärnten im Mittelalter: Mit einem Ausblick bis zum Jahre 1867. Celovec: Kärntner Landesarchiv .

- - -. 2000. Zur Geschichte der Juden in Kärnten. C̆asopis za zgodovino in narodopisje 71/1-2: 95-105. 